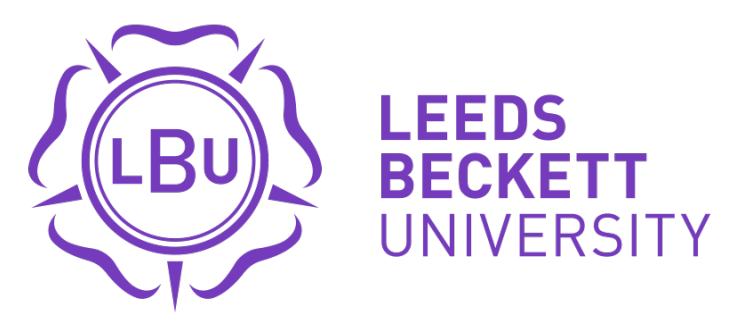

Citation:

Dixey, R and Woodall, J (2011) Prison staff and the health promoting prison. International journal of prisoner health, 7 (4). 8 - 16. ISSN 1744-9200 DOI: https://doi.org/10.1108/17449201111256862

Link to Leeds Beckett Repository record:

https://eprints.leedsbeckett.ac.uk/id/eprint/97/

Document Version:

Article (Accepted Version)

The aim of the Leeds Beckett Repository is to provide open access to our research, as required by funder policies and permitted by publishers and copyright law.

The Leeds Beckett repository holds a wide range of publications, each of which has been checked for copyright and the relevant embargo period has been applied by the Research Services team.

We operate on a standard take-down policy. If you are the author or publisher of an output and you would like it removed from the repository, please contact us and we will investigate on a case-by-case basis.

Each thesis in the repository has been cleared where necessary by the author for third party copyright. If you would like a thesis to be removed from the repository or believe there is an issue with copyright, please contact us on openaccess@leedsbeckett.ac.uk and we will investigate on a case-by-case basis. 


\title{
Prison staff and the health promoting prison
}

\begin{abstract}
Purpose: This paper aims to discuss some of the obstacles to implementing policy and strategy related to health promoting prisons. It focuses on the role of prison officers and raises issues concerning their conditions of service, training and organisational culture in a situation where the prison system faces security issues, overcrowding and high levels of illhealth among prisoners. Design/methodology/approach: This paper emerged as a result of significant overlapping themes between two separate studies conducted by the authors. The paper draws on the authors' qualitative data from these studies. Findings: The findings demonstrate the ambiguities and tensions in changing organisational cultures and among prison staff. Alongside the qualitative data, the paper draws on theory regarding policy implementation at the micro-level to show how staff can block or speed up that implementation. Practical implications: Prison officers are an essential part of health promoting prisons, but have been relatively ignored in the discussion of how to create healthier prisons. Originality/value: The contribution that prison staff make to creating health promoting prisons has been under explored, yet pertinent theory can show how they can be more effectively involved in making changes in organisational culture.
\end{abstract}

Keywords: Prison, prison staff, prison officers, health promotion, health promoting prison, health in prison, settings approach, policy, policy process, 'street level bureaucrats'. 


\section{Prison staff and the health promoting prison}

\section{Introduction}

Drawing on qualitative data from two separate studies, this paper explores progress towards the implementation of policy to create 'health promoting prisons', particularly emphasising the role of prison officers and staff. The contribution that this group make to health promotion in prison has been under explored, yet they are critical in the effective delivery of policy. The paper is centrally concerned with the health promoting prison and how the process of implementation is occurring - or is not - and draws on theory which attempts to explain implementation. We begin by placing health promotion in prison into an historical and political context, summarising the emergence of the World Health Organization's (WHO) health promoting prison concept and Health in Prisons Project (HiPP). We will

critically examine the role of prison officers and staff within the health promoting prison, focussing specifically on whether a cultural or organisational shift is required in order to realise the WHO's vision.

\section{The emergence of the health promoting prison}

To date significant progress has been made in achieving the WHO's ideal of a health promoting prison. However, there remains a clear problem in promulgating key health promoting vales in a prison environment where detention must exist to protect the public. The discourse and ideology of health promotion is incongruous in a setting which curtails individual freedom and choice. Prisons work within hierarchical, disempowering and penalising structures which are fundamentally antithetical to the core values of health 
promotion (Smith, 2000, Whitehead, 2006, Woodall, 2010). Yet, over the past decade there has been considerable policy emphasis concerning health promotion in prisons. Once an activity on the margins of prison policy, health promotion has become a more centralised activity since the publication of key strategies (Department of Health, 2002, HM Prison Service, 2003, Department of Health, 2009, WHO, 2007).

Within the UK national policy drives in England and Wales (Department of Health, 2002; 2004; 2007; HM Prison Service, 2003) and Scotland (Scottish Prison Service, 2002) have been committed to the health promoting prisons movement. In 2002, 'Health Promoting Prisons: A Shared Approach' legitimised and championed a health promotion focus in prison healthcare in England and Wales, advocating the prevention of deterioration in health as well as encouraging prisoners to adopt healthy behaviours (Condon et al., 2007). This policy laid foundations for the Prison Service Order (PSO) on health promotion in 2003 (HM Prison Service, 2003). The PSO sets out required actions for prison governors to promote health as part of a whole prison approach (Condon et al., 2008) and throughout this document there is an underlying premise that health promotion is 'everyone's business' within prison. Caraher et al. (2002, p.227) reiterated this:

"A way needs to be found of developing health promotion as part of the work of every member of prison staff and not an activity that is identified with health care or the running of education groups. This also raises the issue of what is health promotion for the various interested parties?" 


\section{Wider political background}

Concern about offender health has grown concurrently with criticisms in the UK that the prison system as a whole is failing, due, according to the Centre for Social Justice (2009), to government and prison managers struggling to decide the main purpose of imprisonment on a 'getting tough on crime' agenda or a welfare and rehabilitation focus. Critics, for example, have highlighted the exponential growth in the prison population of England and Wales and the high reconviction statistics of released offenders (Ministry of Justice, 2010, Ministry of Justice, 2011). In addition, staff numbers have not kept pace with the rapidly expanding prison population. Recruitment of full time prison officers grew by $9 \%$ between 2000 and 2006, an increase from 24,272 to 26,474 , whilst the prison population increased by 24\% (The Howard League of Penal Reform, 2009). Yet, staff are working with a population with complex, multifaceted health and social problems (Rutherford and Duggan, 2009). In summary, many prisoners are the 'product of profound social breakdown' (The Centre for Social Justice, 2009).

There have also been wider debates concerning the values and principles of the health promoting prison, with some arguing that prisoners' rights should be at the core, including access to good health care (Woodall, 2010). This has been reiterated by the Department of Health who asserts that there need to be equivalent standards of health care for offenders as for the general population, including health promotion (HM Prison Service and NHS Executive, 1999). More recently, 'Our Health, Our Care, Our Say’ (Department of Health, 2006) and the Darzi Report (Darzi, 2008) saw health and social care services being responsive to local needs, particularly those of the most deprived and needy, including offender populations. 


\section{Translating policy into practice}

Policy to address prisoners' health, for example through the PSO, requires prison governors to develop a 'whole prison approach'; however, translating this into practice has not been easy. The WHO have acknowledged that policy formulation at a strategic level may not always be implemented properly in practice (van den Bergh and Gatherer, 2010).

Organisations and institutions have a key role as 'the engine room of the policy process' (Hudson and Lowe, 2004), but not only do institutions find it hard to adapt quickly, resulting in policy inertia, but policy implementation may falter at the stage where it is meant to be implemented by those 'on the ground'. Thus Hudson and Lowe (2004) describe the 'microlevel', where policy outcomes are shaped at the point of final delivery, where individuals have agency to drive and implement policy directives but also have the power to constrain that implementation. Studies have shown, for example, that prison staff disregard health promotion, frequently perceiving it as constituting additional work or something which is outside their professional remit (Bird et al., 1999, Caraher et al., 2002). Three short examples will be drawn from our data to illustrate the complexities of creating healthier prisons and the barriers which may need to be overcome in relation to the role of the prison staff.

\section{Methodology}

This paper emerged as a result of significant overlapping themes between two separate studies conducted by the authors. Data for these studies were collected between 2008 and 2009. Some data from these studies have been published elsewhere (Dixey and Woodall, 
2012), but the specific role of prison staff within the health promoting prison was not considered in those papers. The first study was conducted in three prisons in England by one of the authors and had the broad overarching aim of understanding how values central to the health promotion discourse were applied to the context of imprisonment from the perspective of prisoners and staff (Woodall, 2010). It focussed on the perspectives of both prisoners and prison staff in three category-C prisons. The second study contributing to this paper was an evaluation of a prison visitors' centre in a busy male category-B prison in England holding approximately 1200 prisoners (Dixey and Woodall, 2009). The evaluation was conducted by both of the authors, who were commissioned by the visitors' centre to evaluate their services. Data for the evaluation were generated using interviews and focus groups with prisoners' families, prisoners and prison staff. However, only the data from prison staff have been used in this paper. Further details of each study's design and methods are briefly presented below.

Study 1

Study 1 was conducted in three category-C training prisons in England, all of which held in the region of 550 and 650 sentenced adult male prisoners. Category-C prisoners are defined as:

"Prisoners who cannot be trusted in open conditions but who do not have the ability or resources to make a determined escape attempt." (Leech and Cheney, 2002, p.283) Nineteen prison staff (comprising of 8 prison officers, 5 healthcare staff and 6 staff with other roles, such as administration and occupational health) took part in semi-structured interviews (lasting between 20-45 minutes) as part of the research. 
Gaining entry to these prisons was a multi-layered, convoluted and time-consuming process. Access was, however, negotiated through the Offender Health Research Network (www.ohrn.nhs.uk) and senior governors in each of the prisons. Ethical approval for the research was given by an NHS Research Ethics Committee.

There have been wider discussions on the difficulties of recruiting and sampling prison staff for research purposes. Indeed, the recruitment of prison staff for research purposes can often be more problematic than accessing prisoners themselves. Smith (1996), for instance, found this to be the case, noting that prison staff seemed reluctant to commit themselves to an interview. Similarly, Crawley and Sparks (2005) reported the difficulties in arranging interviews with prison staff and suggested that the regime, time constraints and staffing levels often inhibited the process. Prison staff were originally recruited into this study using Crawley and Sparks' (2005) 'wherever/whenever' approach to prison based recruitment. This is an ad-hoc and unstructured approach to participant recruitment that relies on the availability of staff at a given time. This had a series of flaws and yielded a minimum amount of data. A systematic sampling framework was therefore designed to draw staff participants from various prison departments; this was devised with assistance from the primary gatekeeper in the prisons. The framework identified individuals with diverse job roles within the setting so that further illumination of the prison as a 'whole' institution could be achieved.

Study 2 
Study 2 was an evaluation of a visitors' centre in a Category-B prison. Category-B prisoners have been defined as:

"Prisoners for whom the very highest conditions of security are not necessary, but for whom escape must be made very difficult." (Leech and Cheney, 2002, p.283)

This evaluation had a core component of ascertaining the views of prison staff through three focus groups with a total of fourteen prison staff. Prison staff were selected by prison managers after the authors had outlined that a diverse group of prison staff (in terms of age, experience, rank, job role) participating in the focus groups would be beneficial. The authors were aware of the limitations of prison management recruiting staff; nonetheless, this was the most suitable approach given the limited resources, access and timeframe of the research.

A diverse set of officers (with job remits including: security, visits, offender management and resettlement, gate responsibility and work on residential wings) voluntarily participated in three focus group sessions. Two focus groups were conducted inside the prison in a suitable venue and the third focus group was held outside the prison in an appropriate room within the visitors' centre. Each focus group lasted approximately one hour so that staff were not disrupted significantly from their duties. These sessions were audio recorded after permission and consent was obtained from all participants.

\section{Data analysis}

The data for both projects were analysed in a similar way, using thematic networks, as advocated by Attride-Stirling (2001). Thematic network analysis builds on key features which are predominant in other forms of qualitative data analysis, but is unique in that the aim of the analysis is to construct web-like matrices. This provides insight into the 
researcher's explicit processes from generating interpretation and theory from text and transcripts.

\section{Findings}

Prison staff culture

In our research, prison staff tended to be polarised, either exhibiting a more 'sympathetic', rehabilitative approach to prisoners or a more punitive one, epitomised by an 'us and them' attitude. It was observed (though this needs further verification), that the latter group tended to be those who had not joined the prison service due to a positive choice, but had 'ended up' working in prisons due to other life choices:

"I was up a ladder in the middle of February, it was raining it was cold and I thought I don't want to do this when I was 40 or 50 years old. So I applied for the prison service, fire brigade, police, customs and excise. I was too old for the fire brigade the police and customs and it just boiled down to this job. I never intended doing this job, so here I am sort of 20 years later."

We have found that within the prison staff culture, key aspects of a health promoting prison rehabilitation, family connectedness, and education - are often viewed cynically. For example, prison staff saw roles other than of maintaining security on the wings, as 'soft jobs'. One of our visitors' centre evaluation studies included focus groups with prison staff. These staff suggested that working in the visits hall, where prisoners reconnect with family and children, was:

"... a chance for the wing managers to get rid of the worst members of staff, the ones they don't want on the wing." 
Our research also found, however, that some staff saw the building of relationships with prisoners and their families as an important part of their role, but were frustrated and felt constrained from developing this work. That staff prioritise security and punishment is not surprising, but leads to de-emphasising rehabilitation, pre-release training or seeking gainful employment post-release.

When cultures collide

When interviewing prison staff during the prison visitors' centre evaluation, the authors observed tension when 'cultures collide' or when professional roles potentially conflict. We scrutinised a predominantly voluntary sector funded visitors' centre that worked closely with the prison, and the way in which it maintained family ties through enabling prisoners and family members to see each other. Visitor centre staff were not employed by the prison, but did have access to it, including the visits hall. To gather multiple perspectives of the role and function of the visitors' centre and its staff, focus groups were held with prisoners, prisoners' families and prison staff, including staff working in the visits hall (Dixey and Woodall, 2009).

Our findings highlight the clash of cultures, with prison staff highly suspicious of the work of the visitor centre staff. Prison staff, who felt their remit was to ensure that visitors did not carry drugs into the institution and to maintain security, saw this being jeopardised by involvement of non-uniform staff in the visits process:

"Their remit is not the same as ours so it is always going to cause problems." Some prison staff perceived outside agencies working with a specific aim to rehabilitate prisoners as "fluffy": 
"The less they have to do with the prisoners the better, because they will tell prisoners what they want to hear... whereas we tell the prisoners the truth...they get more and more powers...they are concerned with customer service - we live in the real world."

Clearly some officers felt that the visitors' centre staff had been afforded too much control and power over the visits process. They seemed threatened and that their professional role was being called into question.

Pigeonholing prisoners: 'hardcore' or 'redeemable'

Prison officers were interviewed who all had roles within resettlement, such as helping to find employment or accommodation. It became apparent that they used heuristic devices to categorise prisoners, and that their attitudes were powerful in determining how prisoners would be treated. Prisoners could, on the whole, be divided into 'hardcore' or 'redeemable', in the words of the prison officers. These categories determined how prisoners would be treated by officers, whose role it was to help inmates settle back to 'normal' life after release:

"I put a lot of effort in. There are some people that come into my office with referrals for people and I say I'm not even going to see them. One last week was Andy: Andy is 56 years old, he's been coming in here since he was 16, it doesn't matter what you do for him he'll back in, so it goes straight in the bin. It doesn't matter what you do for him, he'll come straight back."

Another way of categorising prisoners was into those for whom prison was a 'mistake' "where something has just happened", as opposed to the 'career' criminals:

“...where it's always been a matter of course as in from being young they're in trouble, teenager young offenders, mainstream prison, that's been a matter of course from say 16 to him being like 24." 


\section{Discussion}

This paper has attempted to explore aspects of the implementation of policy to develop health promoting prisons and suggests that a vulnerable link in the policy cycle is the point of delivery on the ground, a point where the role of prison officers is vital. Whilst the authors recognise that our research is relatively small in scale and has only ascertained the views of staff in two 'types' of prison establishment (category-C and category-B) it does add to the research in a relatively neglected area. According to Crawley and Crawley (2008), occupational culture is a considerable component of any job and, in prison, occupational norms underpin how staff relate to prisoners and how prison staff respond to institutional change. Surprisingly, this aspect of prison life has been relatively under researched (Crawley and Crawley, 2008). We acknowledge that researchers should be conscious of the diversity that lies behind the apparent homogeneity of settings such as prisons, (Poland et al., 2009) and that staff within prison establishments - even those with the same job role - will differ from each other (Short et al., 2009). Nevertheless, we believe that the research offers insights which may be applicable across the penal system.

Our data fit with critiques provided by, for example, the Prison Reform Working Group (The Centre for Social Justice, 2009), about the training, attitudes and roles of prison staff. It argues that training has not kept appropriate pace with the contemporary role of prison officers. The report states that prisons have become 'warehouses' where staff spend their day 'moving and managing prisoners', neglecting building purposeful relationships. That staff prioritise security and punishment is not surprising, but leads to de-emphasising 
rehabilitation, pre-release training or seeking gainful employment post-release. This is echoed by a serving prisoner who gave evidence to the Centre for Social Justice (2009, p.158):

“Unfortunately education is still often seen as a 'soft touch' by many prison officers and staff."

Another ex-prisoner commented:

"The staff had no motivation to get anyone into gainful employment" (The Centre for Social Justice, 2009, p.182)"

At a macro-level, it could be argued that failure to move more quickly to develop health promoting prisons may be related to the essential contradictions between health promotion ideals and the concept of a prison. Health promotion centralises empowerment, choice and control and espouses an upstream approach. By their nature, prisons strip inmates of control, are disempowering, and by the time of incarceration, a 'downstream', remedial solution is required. This goes to the heart of debates about what modern prisons are for. The idea that prisoners are sent to prison for punishment is outdated; they are certainly sent to prison as punishment, but the emphasis of the modern prison service, especially given the social deprivation faced by the majority of prisoners, is that its chief purpose is rehabilitation, with its concomitant aim of reducing re-offending. This raises key issues regarding the role of the modern prison officer. Our findings resonate with, and lend support to, Tait's (2008) prison officer typology which was based on her research on care and the prison officer. For example, we interviewed staff who Tait classified as 'true carers' as well as 'conflicted officers'. The latter group were characterised by those who "... found it difficult to reconcile care with their pre-occupation with control" (Tait, 2008, p.8). Arguably, those staff who were reluctant to see outside agencies within the prison typified this group. 
The Howard League for Penal Reform (2009) in its outspoken report on the modern prison officer, calls for a 'root and branch review' that questions their role, purpose, professional status and points to a different future. Asking whether they are mere 'turnkeys or professionals', the Howard League makes a case for a wholly graduate profession akin to that of nursing or social work and argues that there is a 'fundamental confusion' about what prison officers should be doing (The Howard League of Penal Reform, 2009). The League calls for nothing short of a transformation in staff recruitment, education and development and, unless change occurs, the League argues that aspirations to reduce re-offending cannot be delivered.

In the same vein, in terms of implementing the health promoting prison concept, unless the role of prison officers is enhanced through more thorough education, better continuing professional development, better remuneration and conditions of service, the drive to develop the prison as a setting for health cannot materialise. We are suggesting that one element of the slowness of policy implementation could be due to the failure to capitalise on the role of prison staff. Other settings approaches, such as the health promoting school, include the health of teaching and other staff. Health promoting schools, have developed a 'look after the staff first' approach (Mason and Rowling, 2005), which addresses quality of life, health and productivity for employees (Kolbe et al., 2005). In work on health in prisons, the focus has been almost exclusively on prisoners (Woodall, 2010). Yet, it is axiomatic that for prisoners to be rehabilitated and released into the community as law abiding, healthy citizens, prison staff need to feel valued and in good physical, mental and psychosocial health (Bögemann, 2007). The health promoting prison must, therefore, embrace both staff and prisoner health if it is to be successful (Ross, 2010). 
No matter how much political support is given to the health promoting prison or how much endorsement is provided by prison governors, front-line prison staff must accept the philosophy and underpinning values if it is to work in reality. The term 'street level bureaucrats' was invented by Lipsky (Lipsky, 1971, Lipsky, 1979) to describe the front line delivery staff who, in his study, had the power to subvert the implementation of new procedures, where the aim had been to develop new policies to end discrimination against disabled children in US state schools. Thus policy was not implemented as designed by the policy makers, but was fashioned by what the 'street level' workers would tolerate or adapt. In our context, prison staff are 'street- level bureaucrats' as they are the front line workers whose co-operation is a vital requirement if the health promoting prisons concept is to succeed, and, according to their inclinations, can block or enhance the implementation of a 'whole prison approach' to health promotion.

Hudson and Lowe (2004) argue that 'ground level' activity is a significant element of the policy process and, if the staff decide to oppose the scheme, could it ever be implemented against their wishes? Whilst some commentators have advocated the use of 'practical checklists' to ensure that policy is implemented as intended (van den Bergh and Gatherer, 2010), our research shows that this may be futile as prison officers have considerable agency in opposing those elements of policy which do not fit with their organisational culture.

\section{Conclusion}

Our research highlights the ambiguity of prison officers in creating the kind of institutional culture which would develop the health promoting prison, showing that they do indeed act as 'street-level bureaucrats', able to block policy implementation. We have presented 
examples where some staff oppose a more rehabilitative approach to offender management, do not see prisoners' health as their concern, or they see it as outside their competence to tackle it. The observable disparity between different prison employees indicates that the organisational culture is changing, but that there is a long way to go. A 'whole prison' approach is not present, and paradoxically, this is demonstrated by the fact that prison officers and staff have been neglected, with little focus on their health needs, their morale, training, or conditions of service. We would endorse the views of those agencies calling for a more highly trained workforce, but this needs to take place alongside a more thorough review of the purposes of a modern prison service, and a transparent discussion of what a health promoting prison might really look like. It is clear that a truly health promoting prison would not only contribute to more effective rehabilitation, but would also make a large contribution to tackling inequalities in health, creating improved well-being for both prison employees and offenders.

\section{References}

Attride-Stirling, J. (2001), “Thematic networks: an analytic tool for qualitative research”, Qualitative Research, Vol. 1 No. 3, pp. 385-405.

Bird, L., Hayton, P., Caraher, M., McGough, H. and Tobutt, C. (1999), "Mental health promotion and prison health care staff in Young Offender Institutions in England", International Journal of Mental Health Promotion, Vol. 1, pp. 16-24. 
Bögemann, H. (2007) "Promoting health and managing stress among prison employees", in Møller, L., Stöver, H., Jürgens, R., Gatherer, A. \& Nikogosian, H. (Eds.), Health in prisons, WHO, Copenhagen, pp. 171-179.

Caraher, M., Dixon, P., Hayton, P., Carr-Hill, R., McGough, H. and Bird, L. (2002), “Are health-promoting prisons an impossibility? Lessons from England and Wales", Health Education, Vol. 102, pp. 219-229.

Condon, L., Hek G. and Harris F. (2007), “A review of prison health and its implications for primary care nursing in England and Wales: the research evidence", Journal of Clinical Nursing. Vol. 16, No. 7, pp. 1201-1209.

Condon L, Hek G. and Harris F. (2008), “Choosing health in prison: prisoners' views on making healthy choices in English prisons”, Health Education Journal. Vol. 67, No. 3, pp. $155-166$.

Crawley E. and Crawley P. (2008), "Understanding prison officers: culture, cohesion and conflict", in Crewe, B. and Wahidin, A. (Eds), Understanding prison staff, Willan Publishing, Cullompton, pp. 134-152.

Crawley, E. and Sparks, R. (2005), "Hidden injuries? Researching the experiences of older men in English prisons", The Howard Journal of Criminal Justice, Vol. 44, pp. 345-356.

Darzi A. (2008), High quality care for all: NHS next stage review final report, Department of Health, London 
Department of Health (2002), Health promoting prisons: a shared approach, Crown, London.

Department of Health (2006), Our health, our care, our say: a new direction for community services, Stationery Office, London.

Department of Health (2009), Improving health, supporting justice: the national delivery plan of the health and criminal justice programme board, Department of Health, London.

Dixey, R. and Woodall, J. (2009), Moving on: an evaluation of the Jigsaw Visitors' Centre, Centre for Health Promotion Research, Leeds Metropolitan University, Leeds.

Dixey, R. and Woodall, J. (2012), “The significance of 'the visit' in an English category-B prison: views from prisoners, prisoners' families and prison staff', Community, Work \& Family, Vol. 15, pp. 29-47.

HM Prison Service (2003), Prison Service Order (PSO) 3200 on health promotion, HM Prison Service, London.

HM Prison Service, NHS Executive (1999), The future organisation of prison health care, DH, London.

Hudson, J. and Lowe, S. (2004), Understanding the policy process: analysing welfare policy and practice, Policy Press, Bristol. 
Kolbe, L., Tirozzi, G., Marx, E., Bobbitt-Cooke, M., Riedel, S., Jones, J. and Schmoyer, M. (2005), "Health programmes for school employees: improving quality of life, health and productivity", Promotion \& Education, Vol. 12, pp. 157-161.

Leech, M. and Cheney, D. (2002), Prisons handbook, Waterside Press, Winchester.

Liebling, A and Price, D. (1998), "Staff-prisoner relationships. A review of the literature", Prison Service Journal. Vol. 120, pp. 3-6.

Liebling, A. and Price, D. (2001), The prison officer,Waterside Press, Winchester.

Liebling, A., Price, D. and Schefer, G. (2011), The prison officer, Willan Publishing, New York.

Lipsky, M. (1971), "Street-level bureaucracy and the analysis of urban reform”, Urban Affairs Quarterly, Vol. 6, pp. 391-409.

Lipsky, M. (1979), Street-level bureaucracy, Russell Sage Foundation, New York.

Mason, J. and Rowling, L. (2005), "Look after the staff first - a case study of developing staff health and well-being", Promotion \& Education. Vol. 12, No. 3-4, pp. 140-141.

Ministry of Justice (2010), Compendium of reoffending statistics and analysis, Ministry of Justice, London. 
Ministry of Justice (2011), Population and capacity briefing for 16th September, 2011.

Ministry of Justice, London.

Poland, B., Krupa, G. and McCall, D. (2009), "Settings for health promotion: an analytic framework to guide intervention design and implementation", Health Promotion Practice, Vol.10 No. 4, pp. 505-516.

Ross, M.W. (2010), "Prison staff occupational health and safety and its relationship with inmate health: a review", Prison Service Journal, Vol. 192, pp. 55-59.

Rutherford, M. and Duggan, S. (2009), "Meeting complex health needs in prison", Public Health, Vol. 123, No. 6, pp. 415-418.

Scottish Prison Service (2002), The health promoting prison. A framework for promoting health in the Scottish Prison Service. Health Education Board for Scotland, Edinburgh.

Short, V., Cooper, J., Shaw, J., Kenning, C., Abel, K. and Chew-Graham, C. (2009), "Custody vs care: attitudes of prison staff to self-harm in women prisoners - a qualitative study", The Journal of Forensic Psychiatry \& Psychology, Vol. 20, pp. 408-426.

Smith, C. (1996), The imprisoned body: women, health and imprisonment. Unpublished PhD thesis, University of Wales, Bangor.

Smith, C. (2000), “'Healthy prisons': a contradiction in terms?”, The Howard Journal of Criminal Justice, Vol. 39 No. 4, pp. 339-353. 
Tait, S. (2008), "Care and the prison officer: beyond 'turnkeys' and 'care bears'”, Prison Service Journal, Vol.180, pp. 3-11.

The Centre for Social Justice (2009), Breakthrough Britain: locked up potential, The Centre for Social Justice, London.

The Howard League of Penal Reform (2009), Turnkeys or professionals? A vision for the 21 st century prison officer, The Howard League of Penal Reform, London.

van den Bergh, B.J. and Gatherer, A. (2010), "The potential of practical checklists in successful health policy review and implementation”, Public Health. Vol. 124, pp. 640-642.

Weatherley, R. and Lipsky, M. (1977), “Street-level bureaucrats and institutional innovation: implementing special education reform”, Harvard Educational Review, Vol. 47, No. 2, pp. 171-197.

Whitehead, D. (2006), "The health promoting prison (HPP) and its imperative for nursing”, International Journal of Nursing Studies, Vol. 43, No. 1, pp. 123-131.

WHO (2007), Health in prisons. A WHO guide to the essentials in prison health, WHO, Copenhagen.

Woodall, J. (2010), Control and choice in three category-C English prisons: implications for the concept and practice of the health promoting prison, Unpublished $\mathrm{PhD}$ thesis, Leeds Metropolitan University, Leeds. 
